\title{
REPRESENTATIONS OF REAL NUMBERS AS SUMS AND PRODUCTS OF LIOUVILLE NUMBERS
}

\author{
P. Erdös
}

A real number $\mathrm{x}$ is a Liouville number if to each natural number $\mathrm{m}$ there corresponds a rational number $h_{m} / k_{m}$, with $k_{m}>1$, such that

$$
0<\left|\mathrm{x}-\mathrm{h}_{\mathrm{m}} / \mathrm{k}_{\mathrm{m}}\right|<\left(1 / \mathrm{k}_{\mathrm{m}}\right)^{\mathrm{m}} .
$$

Some years ago I showed (possibly jointly with Mahler), that every real number is the sum of two Liouville numbers. A proof of the proposition may now be in the literature, but I do not know of any reference. In any case, the following slightly stronger theorem is now needed (see [1]), and therefore I publish a proof.

THEOREM. To each real number $t(t \neq 0)$ there correspond Liouville numbers $\mathrm{x}, \mathrm{y}, \mathrm{u}, \mathrm{v}$ such that

$$
t=x+y=u v
$$

The reciprocal of a Liouville number is again a Liouville number, and therefore we obtain immediately the following proposition.

COROLLARY. Each real number other than 0 is the solution of a linear equation whose coefficients are Liouville numbers.

Proof of the theorem. Since the theorem is trivial for rational $t$, we assume that $t$ is irrational. We also assume, without loss of generality, that $0<t<1$. Let

$$
\mathrm{t}=\sum_{\mathrm{k}=1}^{\infty} \varepsilon_{\mathrm{k}} 2^{-\mathrm{k}} \quad\left(\varepsilon_{\mathrm{k}}=0,1\right),
$$

and write

$$
\mathrm{x}=\sum_{\mathrm{k}=1}^{\infty} \xi_{\mathrm{k}} 2^{-\mathrm{k}}, \quad \mathrm{y}=\sum_{\mathrm{k}=1}^{\infty} \eta_{\mathrm{k}} 2^{-\mathrm{k}}
$$

where, for $\mathrm{n} ! \leq \mathrm{k}<(\mathrm{n}+1) !$

$$
\begin{array}{llll}
\xi_{\mathrm{k}}=\varepsilon_{\mathrm{k}} & \text { and } \quad \eta_{\mathrm{k}}=0 & (\mathrm{n}=1,3,5, \cdots), \\
\xi_{\mathrm{k}}=0 \quad \text { and } \quad \eta_{\mathrm{k}}=\varepsilon_{\mathrm{k}} & (\mathrm{n}=2,4,6, \cdots) .
\end{array}
$$

Then $\mathrm{t}=\mathrm{x}+\mathrm{y}$, and since $\mathrm{x}$ and $\mathrm{y}$ are Liouville numbers, half of the theorem is proved.

To prove the other half, we assume, again without loss of generality, that $t>1$, and we choose a representation of $t$ of the form

Received October 23, 1961. 


$$
t=\prod_{k=1}^{\infty}\left(1+\varepsilon_{k} / k\right) \quad\left(\varepsilon_{k}=0,1\right)
$$

(Clearly, infinitely many nonterminating representations of this form are possible.) Let $\mathrm{m}_{\mathrm{o}}=0$, and let $\left\{\mathrm{m}_{\mathrm{i}}\right\}_{1}^{\infty}$ denote an increasing sequence of positive integers which are to be chosen presently. We write

$$
\begin{gathered}
\mathrm{s}_{\mathrm{i}}=\prod_{\mathrm{m}_{\mathrm{i}-1}<\mathrm{k} \leq \mathrm{m}_{\mathrm{i}}}\left(1+\varepsilon_{\mathrm{k}} / \mathrm{k}\right), \\
\mathrm{u}_{\mathrm{r}}=\prod_{\mathrm{i}=1}^{\mathrm{r}} \mathrm{s}_{2 \mathrm{i}-1}, \quad \mathrm{v}_{\mathrm{r}}=\prod_{\mathrm{i}=1}^{\mathrm{r}} \mathrm{s}_{2 \mathrm{i}}, \\
\mathrm{u}=\lim _{\mathrm{r} \rightarrow \infty} \mathrm{u}_{\mathrm{r}}, \quad \mathrm{v}=\lim _{\mathrm{r} \rightarrow \infty} \mathrm{v}_{\mathrm{r}} .
\end{gathered}
$$

Let $\mathrm{m}_{1}$ be arbitrary. Once $\mathrm{m}_{1}, \mathrm{~m}_{2}, \cdots, \mathrm{m}_{2 \mathrm{r}-1}$ have been chosen, we can make the differences $u-u_{r}$ and $v-v_{r}$ as small as we like by choosing first $m_{2 r}$, and thereafter $m_{2 r+1}$, sufficiently large. Since $u_{r}$ and $v_{r}$ are rational and have denominators that are independent of $\mathrm{m}_{2 \mathrm{r}}$ and $\mathrm{m}_{2 \mathrm{r}+1}$, respectively, we can choose the sequence $\left\{\mathrm{m}_{\mathbf{r}}\right\}$ in such a way that $\mathrm{u}$ and $\mathrm{v}$ are Liouville numbers. This completes the proof.

The following proof is not constructive, but it may be of interest because of its génerality. The set $L$ of Liouville numbers, being a dense set of type $G_{\delta}$, is residual (in other words, it is the complement of a set of first category). Let $A$ and $B$ be any two residual sets of real numbers. For each real number $t$, the set $B_{t}$ of numbers $t-b(b \in B)$ is also residual, and therefore it contains a point $x$ of $A$. Let $y=t-x$. Then $y \in B$, and since $t=x+y$, we have shown that each real number is the sum of a number in $A$ and a number in $B$. We now obtain the first part of our theorem by choosing $\mathrm{A}=\mathrm{B}=\mathrm{L}$. The second part can be proved similarly, under the hypothesis that $t \neq 0$.

\section{REFERENCE}

1. Z. A. Melzak, On the algebraic closure of a plane set, Michigan Math. J. 9 (1962), 61-64.

Budapest, Hungary 